\title{
Psychometric Properties of 2018 Mental Health Module Questions in Ogun State Mandatory Continuous Professional Development Programme for Nurses
}

\author{
OWOEYE, Isaiah Dada RN, RNE, RPN, Msc, FWACN \\ Corresponding author \\ Department of Nursing science, \\ College of Medicine and Health Science \\ Afe Babalola University, Ado-Ekiti, Ekiti state.
OLOWOLAFE, Emmanuel Omoniyi RN, RM, Msc Senior lecturer
Department of Nursing science,
College of Medicine and Health Science
Afe Babalola University, Ado-Ekiti, Ekiti state.

\author{
OPALEYE, Temitope Elizabeth RN, RNE, RPN, Msc \\ School of Psychiatric Nursing, \\ Neuropsychiatric hospital, \\ Aro-Abeokuta, Ogun state.
}

\author{
MAKANJUOLA, John Osuolale RN, RPHN, RNE, Msc \\ Faculty of Nursing Science, \\ University of Medical Sciences, \\ Akure Campus, Ondo State.
}

\author{
OGUNFOWOKAN, Temitope Rukayat RN, RM, Msc \\ Department of Nursing, \\ Olabisi Onabanjo University, \\ Ago-Iwoye, Ogun state.
}

\begin{abstract}
There is a need for instrument standardization to elicit a desired result in the subjects. The study assessed the psychometric properties of 2018 Mental health module questions in Ogun State Mandatory Continuous Professional Development Programme for Nurses. A cross-sectional study was used on the pre and post module results from the participants. Data analysis was done with SPSS window 17. The result showed an internal consistency of 0.249 and reliability coefficient of $\mathbf{- 0 . 1}$. The study concluded that there was inconsistency in the structure of the test items. The recommendation was made that experts in psychometric properties could be involved in the structure of the test items before its administration to nurses.
\end{abstract}

Keywords:- Psychometric properties, Mental health, test items, Mandatory Continuous Professional Development Programme (MCPDP).

\section{INTRODUCTION}

The professional update course in nursing is a veritable tool for professional growth. It is mandatory by the regulatory board of Nursing in Nigeria and it is geared towards making professionals to keeping abreast with information in the areas of practice. The focal aim of the assessment is to determine the potentials of learners as the test score is a pointer to the extent at which the students have learned in a teaching-learning situation [1]. In the organisation of ideas to update the professionals' knowledge, examinations are used and the record is elicited to judge the performance of the participants.
The purpose of examination is to elicit a desired behaviour in an individual which is in tandem with the presented stimulus. Keeping to the laydown rules in structuring the objective questions is important for the relevance of academic aim[2]. The desired behaviour comes through a relatively permanent change in behaviour and this is purposeful in the academic arena. The teachers know the importance of this scenario in the regular academic setting and would not joke with it. The study of the questions test items enables the teacher to define an appropriate test that would be useful in detecting the behaviour of the students in a clear term at any point in time [3]. To do this, needed processes of formulating the stimulus to be presented to the students are needed and these come through active teaching-learning processes. The net issue of determining the responses is the administration of test items in the area that teaching covered.

The update programme is set to make a change in status quo among the attendees and it is important that the instrument is structured in the way to elicit the responses. The reliability of the instrument gives vivid confidence in the teacher that appropriate behaviour would be measured by the instrument. It is expedient to validate the test item of a mental health question in order to keep it in line with standard of practice[4]. The reverse is the case when the instrument does not obey the reliability rule. The outcome from the evaluation gives a direction to the facilitator about the state of the test item to deciding whether the instrument worth being implemented as a deciding factor in determining individual performance [1]. The onus lies on the teachers to design the questions/ test items in such a way that it would be reliable to elicit the necessary 
responses needed for the course. Structuring of the examination questions is important for the future use of the question and could also be diagnostic to detect test items that are not well frames [2]. Some teachers are not academically prepared to determine the reliability of their instrument before the administration in their subjects.

The judgement of behaviour through the test item presented to learner is an ongoing thing in a professional arena. In health training, competence is ensured and basis of evaluation is strongly relied on a good grade from learning experiences as this has implication on nursing service delivery [5]. If the instrument to be used is devoid of value, there is little or no judgement to be placed on such an instrument. This would mean that the purpose for which it is created to elicit a needed response in the learner. There are few documented literatures on the validity of test items among nurses in Nigeria. It is observed that most of the questions for the programme do not obey the rule of evaluation of reliability for the test. The researchers are therefore set to evaluate the reliability of the instrument used in the mental health module for the year 2018.

\section{Objectives of the study}

- To determine the internal consistency of the test items.

- To determine the reliability of the instrument.

\section{METHODS AND MATERIALS}

The cross-sectional study was used to access the psychometric properties of the Mental Health Questions of March edition of MCPDP among the participants in Ogun state. Data were elicited from nurses from different areas of speciality, varying age and both gender. These nurses were participants documented for March 2018 programme. The total number of the participants was 150 . The test items comprise of questions submitted by the facilitator and collated by the organisers and these were administered to the respondents. Data were collected following their consent. Test retest reliability was done using Pearson Product Moment Correlation. Data were analysed using SPSS window 17 . The result revealed an internal consistency of 0.249 and reliability of -0.1 . Ethical approval for data collection was from the Ogun State Committee of MCPDP.

\section{RESULT}

\begin{tabular}{|c|c|c|}
\hline Pre and Post & Cronbach Alpha & No of items \\
\hline March 2018 & .249 & 2 \\
\hline
\end{tabular}

Table 1:- Internal consistency of the test items

\begin{tabular}{|c|c|c|c|}
\hline & & Pre-March & Post-March \\
\hline \multirow[t]{3}{*}{ premarch } & Pearson Correlation & 1 & $-1.000^{* * *}$ \\
\hline & Sig. (2-tailed) & & . \\
\hline & $\mathrm{N}$ & 2 & 2 \\
\hline \multirow[t]{3}{*}{ post-march } & Pearson Correlation & $-1.000^{* *}$ & 1 \\
\hline & Sig. (2-tailed) & . & \\
\hline & $\mathrm{N}$ & 2 & 2 \\
\hline
\end{tabular}

Table 2:- Reliability of the instrument

\section{DISCUSSION}

\section{$>$ Internal consistency of the test items:}

The study showed that internal coefficient of the test items in the mental health module of the MCPDP is 0.249. This is in contrast with a study by Cucolo \& Perroca [6] study where result was 0.85 on the inter-questions correlation of the instrument on nursing care product (APROCENF). In a study by Quaigrain \& Kwamina [2], the researcher utilized the Kuder-Richardson 20 coefficient and it was revealed that the internal consistency of the question was 0.77 . In another study by Desalu et. al., [7] it was documented that the questionnaire had 0.85 content validity and its test-retest reliability index using Kappa coefficient yielded $0.546-0.897$ which shows that the instrument is reliable. In another study by Castro, Palha, Martins \& Oliveira[8], the internal consistency of the perception scale of an instrument used in accessing the daily practices of community mental health workers had a satisfied attribute as the value of its Cronbach's alpha revealed 0.76 overall, and $<0.75$ in differs categories. In a study by Roldan-Merino [9], internal consistency of the instrument was 0.89 on 39 test-items and this indicative of satisfactory internal consistency of the instrument. In another study by Côté, Orri \& Brendgen et. al., [10] on Psychometric properties of the Mental Health and Social Inadaptation Assessment for Adolescents, the instrument used was rated to have a better to best range of internal consistency of Alpha=0.70-0.97. In a study by Bilberg, Norgaard, Roessler \& Overgaard[11], on a 38 question Common Mental Disorders Questionnaire (CMDQ), the internal stability of the questionnaire was reported as 0.94 using Cronbach's alpha and this revealed that there is high level of internal consistency of the test items

\section{$>$ Reliability of the instrument:}

The present study revealed that the correlation coefficient ( $\mathrm{r}$ ) is significant at $\mathrm{P}<0.05(\mathrm{r}=0.01,, \mathrm{P}<0.05)$. In a study by Roldan-Merino [9], a month test-retest reliability of the instrument called 'Positive Mental Health Questionnaire in a sample of Spanish university students' was carried out and the reliability was $0.92(n=380)$. This 
was reported to be desirable on the dimensions of the instrument. In another study by Bilberg, Norgaard, Roessler \& Overgaard[11], where test-retest reliability was used on a 38 question Common Mental Disorders Questionnaire (CMDQ), the reliability coefficient was between 0.42 to 0.98. The same study concluded that there is a fair to perfect reliability of the instrument. However, the researcher stated that the lower figure 0.42 reliability should not be regarded to an issue since further evaluations would be carried out on the subjects. In a review by Duncan, Comeau \& Wang et. al., [12], the researchers worked on 202 reliability from 31 fitted studies, the study revealed 0.58 reliability with range of $0.53-0.63$. In a study by Ghazali [1], where an instrument was structured based on reviewed literature mostly from the countries in Asia, the study revealed the value between 0.61 and 0.992 which is reported to be reliable as documented that value above 0.7 is valid. In this same study, some text items were deleted which favoured the increment in the value of the reliability index.

\section{CONCLUSION}

The study concluded that there was weakness in the structure of the test items of the 2018 March edition of Mental health module question in the MCPDP. It is therefore imperative that the organiser of the programme should critically examine the questions being submitted by the facilitator to ensure that they are well structured before it is administered to the participants. It is also important that experts in psychometric properties be involved in the formulation of the test items prior to its utilization in measuring the performances of the participants.

\section{REFERENCES}

[1]. Ghazali, NHM. A Reliability and Validity of an Instrument to Evaluate the School-Based Assessment System: A Pilot Study. International Journal of Evaluation and Research in Education (IJERE) Vol.5, No.2, June 2016, pp. 148-157

[2]. Quaigrain K \& Kwamina AA. Using reliability and item analysis to evaluate a teacher-developed test in educational measurement and evaluation, Cogent Education 2017, 4:1, DOI: 10.1080/2331186X.2017.1301013

[3]. Souza AC, Alexandre NMC \& Guirardello EB. Psychometric properties in instruments evaluation of reliability and validity. Epidemiol Serv Saude. 2017 Jul-Sep;26(3):649-659. doi: 10.5123/S1679

[4]. Hammarström, A., Westerlund, H., Kirves, K., Nygren, K., Virtanen, P., \& Hägglöf, B. Addressing challenges of validity and internal consistency of mental health measures in a 27- year longitudinal cohort study - the Northern Swedish Cohort study. BMC medical research methodology, 2016; 16, 4. https://doi.org/10.1186/s12874-015-0099-6

[5]. Ali SH, Carr PA \& Ruit K. Validity and Reliability of Scores Obtained on Multiple-Choice Questions: Why Functioning Distractors Matter. Journal of the
Scholarship of Teaching and Learning, 2016; Vol. 16, No. 1, pp.1-14. doi: 10.14434/josotl.v16i1.19106

[6]. Cucolo DF \& Perroca MG. Assessment of the nursing care product (APROCENF):A reliability and construct validity study. Rev. Latino-Am. Enfermagem 2017; Vol.25 http://dx.doi.org/10.1590/15188345.1495.2860

[7]. Desalu OO, Aladesanmi AO, Ojuawo OB, Opeyemi CM, Ibraheem RM, Suleiman ZA, et al. Development and validation of a questionnaire to assess the doctors and nurses knowledge of acute oxygen therapy. PLoS ONE 2019; 14(2): e0211198. https://doi.org/10.1371/journal.pone.0211198

[8]. Castro UR, Palha AJP, Martins JCA \& Oliveira NR. Reliability of a questionnaire assessing daily practices of community mental health workers. Acta paul. enferm. 2016; vol.29 no.6 São Paulo. https://doi.org/10.1590/1982-0194201600097

[9]. Roldan-Merino J,Casa I, Lluch-Canut T \& SanromaOrtiz M. Reliability and validity of the Positive Mental Health Questionnaire in a sample of Spanish university students. Journal of Psychiatric and Mental Health Nursing. 2017; 24(1365-2850):1-11

[10]. Côté, S. M., Orri, M., Brendgen, M., Vitaro, F., Boivin, M., Japel, C., Séguin, J. R., Geoffroy, M. C., Rouquette, A., Falissard, B., \& Tremblay, R. E.. Psychometric properties of the Mental Health and Social Inadaptation Assessment for Adolescents (MIA) in a population-based sample. International journal of methods in psychiatric research 2017, 26(4), e1566. https://doi.org/10.1002/mpr.1566

[11]. Bilberg, R., Nørgaard, B., Roessler, K. K., \& Overgaard, S. Test-retest reliability of Common Mental Disorders Questionnaire (CMDQ) in patients with total hip replacement (THR). BMC psychology 2014, 2(1), 32. https://doi.org/10.1186/s40359-0140032-5

[12]. Duncan L, Comeau J, Wang L, Vitoroulis I, Boyle MH \& Bennet K. Research Review: Test-retest reliability of standardized diagnostic interviews to assess child and adolescent psychiatric disorders: a systematic review and meta-analysis. The Journal of Child Psycology and Psychiatry 2018. https://doi.org/10.1111/jcpp.12876 